NEUROGASTROENTEROLOGY

\title{
A randomised controlled trial assessing the efficacy and safety of repeated tegaserod therapy in women with irritable bowel syndrome with constipation
}

\author{
J Tack, S Müller-Lissner, P Bytzer, R Corinaldesi, L Chang, A Viegas, S Schnekenbuehl, \\ C Dunger-Baldauf, P Rueegg
}

See end of article for authors' affiliations

Correspondence to: Dr J Tack, Department of Internal Medicine, Division of Gastroenterology, University Hospital Gasthuisberg, Herestraat 49, B-3000 Leuven, Belgium; Jan.Tack@med. kuleuven.ac.be

Accepted 24 June 2005 Published online first 19 August 2005

Background: It has been proposed that treatments for irritable bowel syndrome with constipation (IBS-C) should provide rapid symptomatic relief, be intermittent, and effective upon repeated use.

Aims: To evaluate the efficacy and safety of tegaserod on IBS symptoms, and its impact on quality of life and health economic measures.

Patients: Women ( $\geqslant 18$ years of age) with IBS-C according to the Rome II criteria.

Methods: Prospective, double blind, placebo controlled, randomised trial. Women with IBS-C either received tegaserod $6 \mathrm{mg}$ twice daily or placebo for one month. Patients with at least a partial response entered a treatment free interval. Upon symptom recurrence, tegaserod treated patients were re-randomised to tegaserod or placebo for an additional month. Primary efficacy variables were response (overall IBS symptoms and abdominal discomfort/pain) to first and repeated treatment. Analysis was by intention to treat.

Results: 2660 patients and 1191 patients were randomised for first and repeated treatment respectively. Tegaserod was superior to placebo for each primary efficacy variable (first treatment: $33.7 \%$ v $24.2 \%$ responders respectively for relief of IBS symptoms and $31.3 \% \vee 22.1 \%$ for relief of abdominal discomfort/ pain; repeated treatment: $44.9 \%$ v $28.7 \%$, and $42.4 \%$ v $27.1 \%$, all $p<0.0001$ ). Tegaserod was superior to placebo for every secondary efficacy variable (relief of abdominal discomfort/pain, bloating and constipation; stool frequency and consistency). A response to tegaserod was observed within the first treatment week. Tegaserod produced greater satisfaction, work productivity, and improved quality of life than placebo $(p<0.05)$.

Conclusion: Tegaserod provides rapid and sustained relief of IBS-C symptoms both during first and repeated treatment.

I: rritable bowel syndrome (IBS) is characterised by multiple chronic symptoms (abdominal discomfort/pain, altered bowel habits, bloating), which vary in intensity, and has a point prevalence of $10-15 \%$ in Western countries. ${ }^{1}$ Continuous treatment over 12 weeks with the $5-\mathrm{HT}_{4}$ receptor agonist tegaserod improves symptoms in women with IBS with constipation (IBS-C). ${ }^{23}$ Given the intermittent nature of symptoms, shorter treatment courses with repeated treatment upon symptomatic relapse might be an attractive option for many patients. Repeated treatment is often necessary in IBS-C, as symptoms almost invariably return over time, but has not been subject to controlled studies. In 2003, the European Committee for Medicinal Products for Human Use (CHMP) published "Points to Consider" on the conduct of clinical trials in IBS, ${ }^{4}$ recommending the use of a rerandomisation design and two primary outcome variables for drugs intended for short term symptomatic relief of IBS. Uncontrolled data suggest that repeated treatment is effective in IBS-C patients responding to initial tegaserod therapy. ${ }^{5-7}$ The current study was a controlled trial designed to evaluate the efficacy and safety of repeated treatment with tegaserod, and assess the impact of tegaserod on quality of life (QoL) and health economic measures in IBS-C.

\section{METHODS}

Study design

This prospective, double blind, randomised, multicentre trial was designed to study the efficacy and safety of first and repeated tegaserod treatment in women with IBS-C. It included a four week screening period, a two week baseline period (no study medication), and two four week placebo controlled treatment periods (first and repeated treatments), separated by a treatment free interval (TFI) (fig 1). During first treatment, patients received either tegaserod $6 \mathrm{mg}$ twice daily or placebo for four weeks (allocation ratio 4:1). This ratio was used to ensure a sufficient number of patients for the primary efficacy evaluation of repeated treatment. The random allocation sequences were generated by an automated system which was independent of the investigator and study sponsor. The codes were kept confidential until the end of the study when the randomisation code was broken. All patients, study investigators, and sponsor's staff were blinded to the randomisation codes and the screening and follow up study assessments were completed by study personnel who were blinded to the randomisation code. Patients with at least a partial response (satisfactory relief of either overall IBS symptoms for at least two of the first four treatment weeks or abdominal discomfort/pain in at least two of the first four treatment weeks) entered the TFI. The TFI (212 weeks) depended on the time to recurrence of IBS symptoms after the end of first treatment. If symptoms recurred within 12 weeks (absence of satisfactory relief of overall IBS symptoms for at least three out of four consecutive weeks and abdominal discomfort/pain for at least three out of four consecutive weeks) patients were eligible for repeated treatment. Subjects without recurrence

Abbreviations: CHMP, Committee for Medicinal Products for Human Use; IBS-C, irritable bowel syndrome with constipation; QoL, quality of life; TFI, treatment free interval. 
of their symptoms within 12 weeks were not studied further. Patients who received tegaserod during first treatment were re-randomised to either tegaserod or placebo (ratio 1:1); those receiving placebo during first treatment were mock randomised to tegaserod in the repeated treatment period. This allowed for the treatment blind to be maintained while ensuring that each patient who experienced at least a partial response during first treatment received active treatment during at least one four week cycle.

\section{Concomitant medications}

Medications affecting gastrointestinal motility and/or visceral perception were not permitted for the entire duration, including the TFI. Bisacodyl or another pre-agreed laxative could be used as rescue medication by patients without a bowel movement for $\geqslant 96$ hours and no less than moderate ( 3 or 4 on the daily scale) lower abdominal discomfort/pain or bloating.

\section{Patient population}

\section{Inclusion/exclusion criteria}

Women ( $18-65$ years of age) meeting Rome II criteria for IBS- $\mathrm{C}^{8}$ and having experienced abdominal discomfort/pain with two of the following characteristics: (1) relief with defecation; (2) onset associated with a change in stool frequency; (3) onset associated with a change in stool form, for at least 12 weeks (not necessarily consecutive) during the previous 12 months were included. Patients had to have previously used non-pharmacological therapy (for example, diet and lifestyle changes) for two months or more without adequate improvement of their IBS-C symptoms. Patients were excluded if they had diarrhoea at least $25 \%$ of the time during the previous three months, any history of cathartic colon or laxative abuse, or any other significant bowel disorders. Women were recruited mainly from secondary and tertiary care settings. Patients who had previously used tegaserod (clinical trials or commercially available) were allowed if their last dose was $>30$ days before study entry.

\section{Study assessments}

Visits took place at screening, start of baseline (day-14), and on the first and last day (that is, days 1 and 29) of both treatment periods. During the TFI, visits occurred monthly. Patients recorded all symptoms and intake of study medication or laxative in an electronic patient diary. Use of concomitant medication and adverse events were recorded at each visit. Additional safety data, such as haematology, blood chemistry, urinalysis, physical condition, electrocardiograms (ECGs), and vital signs were monitored.

Primary efficacy was assessed using a binary scale based on the patient answers to the following weekly questions: "Did you have satisfactory relief of your overall IBS symptoms during the last week?" and "Did you have satisfactory relief of your abdominal discomfort or pain during the last week?" The question on "satisfactory relief" has previously been used in studies of tegaserod ${ }^{10}$ and "satisfactory relief" has been shown to best represent individual perception of relief in overall IBS symptoms, discomfort, and pain. ${ }^{11}{ }^{12}$ Secondary efficacy parameters included weekly assessment of constipation relief (binary scale) and daily assessment of abdominal discomfort/pain, bloating, stool consistency, all using a 7point scale, and stool frequency. Patients were asked to assess their overall satisfaction with treatment at the end of each treatment period. Additionally, patients completed the IBS

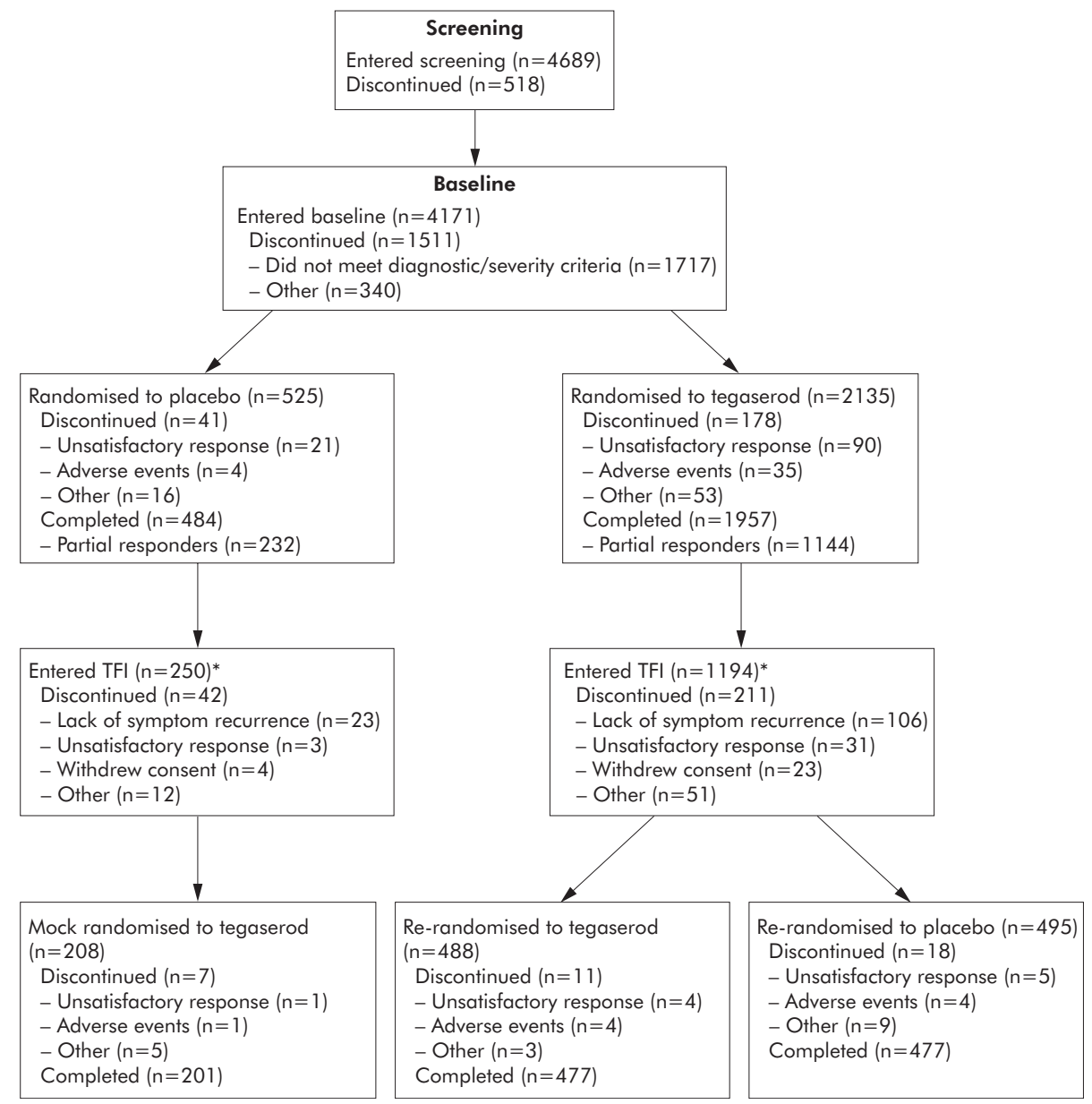

Figure 1 Flow chart depicting the selection and evolution of patients, during the different phases of the study. *Includes patients who entered the treatment free interval (TFI) without having met the partial response criteria. 
specific QoL questionnaire (IBS-QoL), ${ }^{13}$ Work Productivity Activity Impairment for IBS with Constipation (WPAI:IBSC),${ }^{14}$ and the health related QoL EQ-5D ${ }^{15}{ }^{16}$ questionnaires at baseline and at the end of first and repeated treatment. WPAI:IBS-C and EQ-5D were also assessed after two weeks during both treatment periods. Primary, secondary assessments, and QoL, WPAI:IBS-C, and EQ-5D questionnaires were completed by patients using an electronic patient diary. As a result of a programming error with the electronic patient diaries, IBS-QOL, WPAI:IBS-C, and EQ-5D data for the repeated treatment period could not be analysed; therefore, only results for the first treatment period are reported here.

\section{Statistical methods}

By simulation, sample sizes of 2000 patients in the tegaserod group and 500 patients in the placebo group for the first treatment period were found to be sufficient to detect differences between tegaserod and placebo of $15 \%$ in responder rates for relief of overall IBS symptoms and 10\% for relief of abdominal discomfort/pain during first and repeated treatment simultaneously with $90 \%$ power at a two sided significance level of 0.05 .

The four primary efficacy variables were response for relief of overall IBS symptoms and relief of abdominal discomfort/ pain for both first and repeated treatment. Response was defined as at least three weeks with satisfactory relief during four weeks of treatment (75\% rule). Secondary efficacy variables included response based on a $50 \%$ rule as proposed by the $\mathrm{CHMP}^{4}$ ( similar to the $75 \%$ rule, but using at least two out of four weeks with satisfactory relief), response for weekly relief of constipation (75\% rule), daily diary assessments, and their weekly averages. Weekly improvement in abdominal discomfort/pain or bloating was defined as $a \geqslant 1$ point reduction from baseline.

Comparisons between treatment groups for repeated treatment were restricted to patients initially treated with tegaserod. Sequentially rejective multiple testing was applied to the primary efficacy variables using a predefined order to maintain an overall 5\% type I error rate. Response variables were compared between treatments using a Cochran-MantelHaenszel test adjusting for centre (primary response, repeated treatment: additionally for first treatment response). The daily (week 1 to assess onset of effect) and weekly non-binary variables were evaluated by mixed linear model analysis. The binary variables were evaluated by the generalised estimating equation method, the factors being treatment, centre, and timepoint. Time to recurrence was analysed by the log rank test. ANCOVA, with the factors treatment, centre, and covariates age, baseline score, was

Table 1 Baseline characteristics (randomised patients in first treatment period)

\begin{tabular}{|c|c|c|}
\hline & $\begin{array}{l}\text { Tegaserod } \\
(n=2135)\end{array}$ & $\begin{array}{l}\text { Placebo } \\
(n=525)\end{array}$ \\
\hline $\begin{array}{l}\text { Mean age, years (range) } \\
\text { Premenopausal (\%) } \\
\text { Mean duration of IBS symptoms, years } \\
\text { (range) } \\
\text { Patients' most bothersome symptom, } \\
\text { n (\%)* } \\
\text { Constipation } \\
\text { Abdominal discomfort/pain } \\
\text { Bloating } \\
\text { Othert } \\
\text { Use of tegaserod before study }\end{array}$ & $\begin{array}{l}41.9(17-66) \\
1349(63.2) \\
13.1(0.3- \\
59.0)\end{array}$ & $\begin{array}{l}42.6(18-65) \\
320(61.0) \\
13.4(0.2- \\
55.0)\end{array}$ \\
\hline \multicolumn{3}{|c|}{$\begin{array}{l}\text { *Each patient reported one symptom that they viewed as their main } \\
\text { complaint during the three months preceding study entry. } \\
\text { TThese included infrequent defecation, feeling of incomplete evacuation, } \\
\text { hard stools, and straining. }\end{array}$} \\
\hline
\end{tabular}

Table 2 Relief of overall IBS symptoms and abdominal discomfort/pain: $50 \%$ rule

\begin{tabular}{|c|c|c|c|c|}
\hline & \multicolumn{2}{|c|}{ First treatment } & \multicolumn{2}{|c|}{ Repeated treatment ${ }^{\star}$} \\
\hline & $\begin{array}{l}\text { Tegaserod } \\
(n=2135)\end{array}$ & $\begin{array}{l}\text { Placebo } \\
(n=525)\end{array}$ & $\begin{array}{l}\text { Tegaserod } \\
(\mathrm{n}=488)\end{array}$ & $\begin{array}{l}\text { Placebo } \\
(n=495)\end{array}$ \\
\hline $\begin{array}{l}\text { Overall IBS symptoms, } \\
\text { responder rate }\end{array}$ & $50.5 \%$ & $39.8 \%$ & $60.5 \%$ & $42.8 \%$ \\
\hline $\begin{array}{l}\text { Treatment difference } \\
(95 \% \mathrm{Cl})\end{array}$ & $10.6 \% 16.0$ & $-15.1)$ & $17.0 \%(11.2$ & $2-22.7)$ \\
\hline p Value & $<0.0001$ & & $<0.0001$ & \\
\hline NNT & 9.4 & & 5.9 & \\
\hline $\begin{array}{l}\text { Abdominal discomfort/ } \\
\text { pain, responder rate }\end{array}$ & $47.8 \%$ & $38.7 \%$ & $58.8 \%$ & $38.8 \%$ \\
\hline $\begin{array}{l}\text { Treatment difference } \\
(95 \% \mathrm{Cl})\end{array}$ & $9.0 \%(4.5-$ & $-13.5)$ & $19.9 \%(14.2$ & $2-25.7)$ \\
\hline p Value & 0.0002 & & $<0.0001$ & \\
\hline NNT & 11.1 & & 5.0 & \\
\hline \multicolumn{5}{|c|}{$\begin{array}{l}\text { *Includes only first treatment tegaserod patients who received repeated } \\
\text { treatment. } \\
\text { NNT, numbers needed to treat. }{ }^{17}\end{array}$} \\
\hline
\end{tabular}

applied to QoL and health economic measures. Nominal $\mathrm{p}$ values (two sided) are shown. Analysis was by intention to treat. Post hoc comparisons of adverse event rates $(\geqslant 1 \%$ in any group) used Fisher's exact test.

\section{Study conduct}

The study protocol was approved by ethics committees at all participating centres and performed according to the Declaration of Helsinki and the principles of good clinical practice. All patients gave written informed consent.

\section{Role of funding source}

The sponsor planned and conducted the study, and analysed the resulting data. Authors had full access to all the data from the study, were involved in data interpretation, produced and directed the manuscript, which was further developed in collaboration with the sponsor, and had final responsibility for the decision to submit for publication.

\section{RESULTS \\ Patient population, baseline characteristics, and treatment}

A total of 4689 women from 267 centres in 24 countries were screened, and 2660 were eventually randomised (fig 1). Demographic and baseline characteristics were similar across treatment groups at baseline (table 1) and at entry to repeated treatment. Most patients were white $(82.1 \%)$ and aged $25-$ 55 years $(75 \%)$. Laxative intake during each study period was infrequent and balanced between treatment groups.

Of 2135 patients treated with tegaserod ( 525 placebo) in the first treatment period, 1194 (250 placebo) entered the TFI. Of the patients initially treated with tegaserod, 983 qualified for repeated treatment and were re-randomised to tegaserod (488) or placebo (495).

\section{Primary efficacy outcomes ("75\% rule")}

Tegaserod was significantly superior to placebo for all four primary efficacy variables (response for relief of overall IBS symptoms and relief of abdominal discomfort/pain during both first and repeated treatment; fig 2). In the mock randomised group, responder rates during repeated treatment were $41.8 \%$ and $36.5 \%$ for relief of overall IBS symptoms and relief of abdominal discomfort/pain, respectively.

\section{Secondary efficacy outcomes}

Responder rates (50\% rule) were significantly greater with tegaserod than placebo during first and repeated treatment 

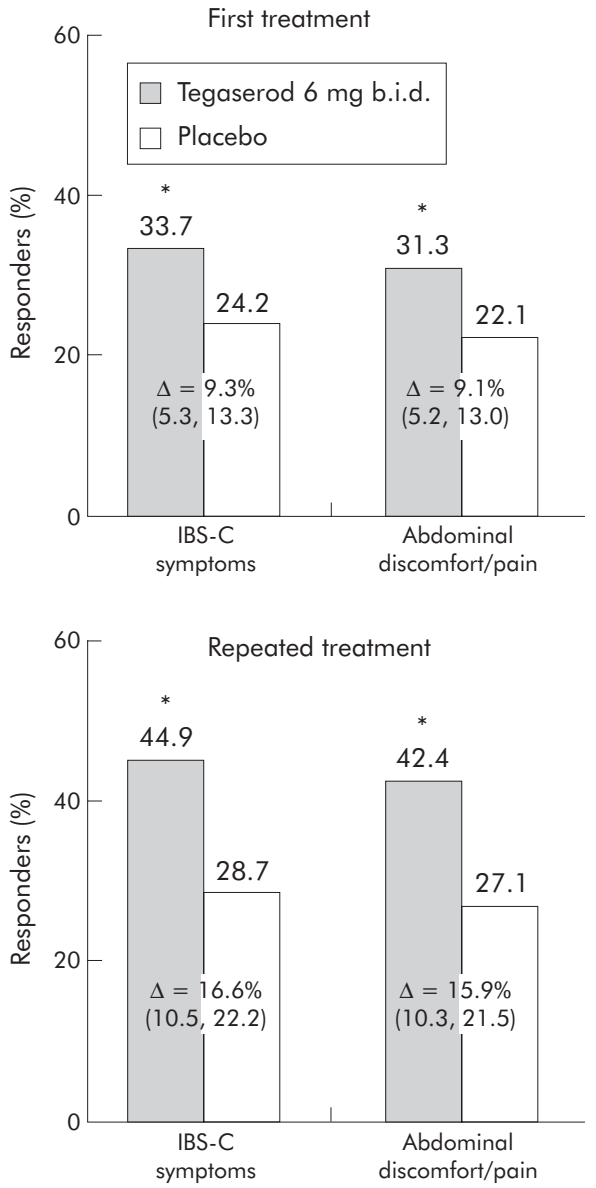

Figure 2 Response rate for relief of overall IBS symptoms and for relief of abdominal discomfort/pain during both first and repeated treatment. During both treatment periods, relief was significantly ( $\left.{ }^{*} p<0.0001\right)$ greater with tegaserod than with placebo. For repeated treatment, both tegaserod and placebo groups had received tegaserod in first treatment. $\Delta=$ difference in response rate ( $95 \%$ confidence interval).

(table 2). The treatment differences for the responder rates based on the $50 \%$ and the $75 \%$ rule were comparable.

For both overall IBS symptoms and abdominal discomfort/ pain, the weekly proportion of patients with satisfactory relief was significantly $(p<0.05)$ greater with tegaserod than placebo for all weeks during first and repeated treatment. This indicates onset of the effect in week 1, which was then sustained in weeks 2-4. The more precise day of onset of effect in week 1 , as reflected by daily recorded symptoms, and other key secondary efficacy variables, is summarised in table 3 and figure 3 .

During the TFI, a gradual recurrence of symptoms occurred after both placebo and tegaserod treatment. No rebound effect (rapid exacerbation of gastrointestinal symptoms beyond pretreatment levels) was observed in tegaserod treated patients for any individual IBS symptoms (abdominal discomfort/pain, bloating, bowel movements, stool consistency). The threshold for symptom recurrence during the TFI was not reached in 143 patients $(6.7 \%)$ in the tegaserod group and 30 patients $(5.7 \%)$ in the placebo group. These patients were not eligible for repeated treatment. For patients with symptomatic recurrence, slightly lower severity levels were observed in the tegaserod group before repeated treatment than before first treatment (for example, $3.7 v$ 4.0 for discomfort/pain, $3.9 v 4.2$ for bloating). Similar results were observed in the placebo group. The median time to recurrence was 4.0 weeks for tegaserod treated patients and
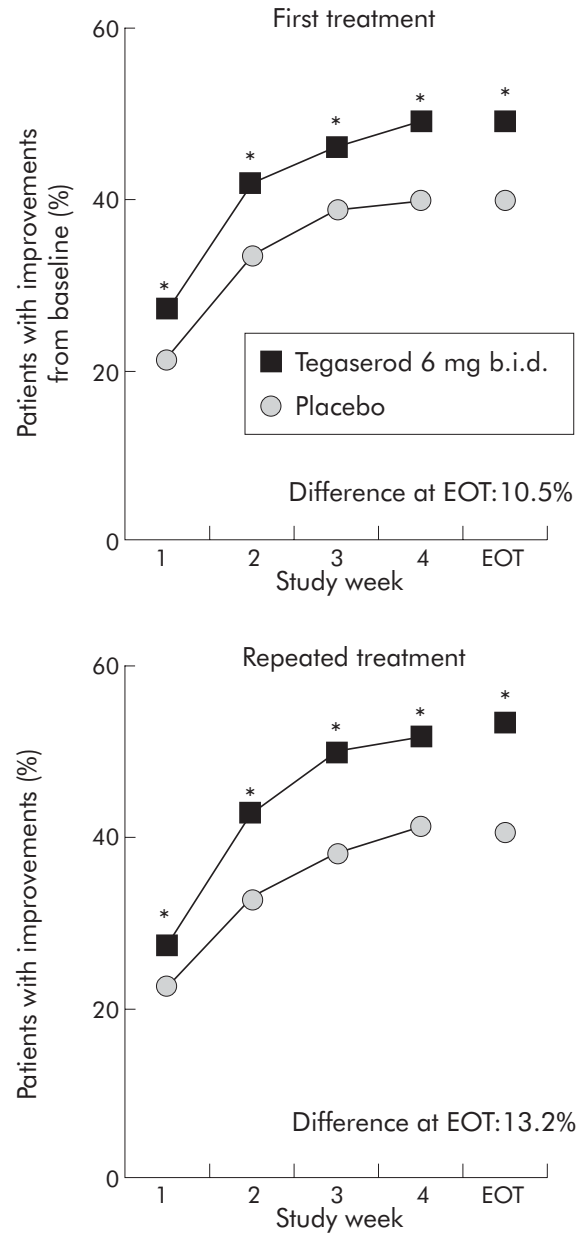

Figure 3 Weekly proportion of patients with satisfactory relief during first and repeated treatment. During both treatment periods, the weekly proportion of patients with satisfactory relief was significantly $\left({ }^{*} p<0.05\right)$ greater with tegaserod than placebo for all weeks. For repeated treatment, both tegaserod and placebo groups had received tegaserod in first treatment. EOT, end of treatment.

4.7 weeks for patients administered placebo. The difference was not statistically significant.

\section{QoL and health economics related outcomes}

Tegaserod significantly improved IBS-QoL scores and improved work productivity scores compared with placebo during the first treatment period $(\mathrm{p}<0.05)$. Significantly more patients in the tegaserod than the placebo group reported overall treatment satisfaction with first and repeated treatment (fig 4), including greater relief of IBS symptoms compared with previous medication, greater willingness to use the drug in the future, and greater willingness to recommend it to others with IBS.

Patients treated with tegaserod had significantly greater work productivity in the first treatment period than those receiving placebo as measured by the WPAI:IBS-C, including less presenteeism (less impairment while at work), less absenteeism (less work time missed), less work impairment (combination of presenteeism and absenteeism), and less activity impairment $(\mathrm{p}<0.05)$. Detailed results on WPAI:IBSC, EQ-5D, and IBS-QOL will be presented elsewhere.

Safety and tolerability

The safety profile of tegaserod was similar to that seen in previous studies (table 4). Headache and diarrhoea were 
Table 3 Summary of secondary efficacy outcomes

\begin{tabular}{|c|c|c|c|c|c|c|}
\hline & \multicolumn{3}{|c|}{ First treatment } & \multicolumn{3}{|c|}{ Repeated treatment ${ }^{*}$} \\
\hline & $\begin{array}{l}\text { Tegaserod } \\
(\mathrm{n}=2135)\end{array}$ & $\begin{array}{l}\text { Placebo } \\
(n=525)\end{array}$ & p Value & $\begin{array}{l}\text { Tegaserod } \\
(\mathrm{n}=488)\end{array}$ & $\begin{array}{l}\text { Placebo } \\
(n=495)\end{array}$ & p Value \\
\hline $\begin{array}{l}\text { Improvement† in abdominal discomfort/pain } \\
\text { Statistically significant difference tegaserod } v \text { placebo reached by } \neq \\
\text { Improvement† in bloating } \\
\text { Statistically significant difference tegaserod } v \text { placebo reached by } \ddagger \\
\text { Relief of constipation ( } 75 \% \text { rule) } \\
\text { Mean stool consistency, change from baseline } \\
\text { Statistically significant difference tegaserod } v \text { placebo reached by } \neq \\
\text { Weekly bowel movements, change from baseline } \\
\text { Statistically significant difference tegaserod } v \text { placebo reached by } \ddagger\end{array}$ & $\begin{array}{l}52.5 \% \\
\text { Day } 3 \\
50.6 \% \\
\text { Day } 3 \\
39.4 \% \\
-1.1 \\
\text { Day } 1 \\
2.5 \\
\text { Day } 1\end{array}$ & $\begin{array}{l}42.8 \% \\
40.1 \% \\
24.8 \% \\
-0.7 \\
1.3\end{array}$ & $\begin{array}{l}<0.0001 \\
<0.0001 \\
<0.0001 \\
<0.0001 \\
<0.0001\end{array}$ & $\begin{array}{l}54.2 \% \\
\text { Day } 3 \\
54.4 \% \\
\text { Day } 3 \\
45.1 \% \\
-0.9 \\
\text { Day } 1 \\
2.2 \\
\text { Day } 2\end{array}$ & $\begin{array}{l}41.8 \% \\
41.2 \% \\
27.5 \% \\
-0.6 \\
1.5\end{array}$ & $\begin{array}{r}<0.0001 \\
<0.0001 \\
<0.0001 \\
0.0003 \\
0.0013\end{array}$ \\
\hline
\end{tabular}

reported more frequently in patients receiving tegaserod than placebo. The profile of adverse events with repeated treatment was similar to that seen with first treatment.

The only adverse event reported significantly $(p<0.05)$ more frequently with tegaserod than placebo was diarrhoea. Transient diarrhoea occurred in $<5 \%$ of tegaserod treated patients during first treatment and $<2 \%$ during repeated treatment. Most patients experiencing diarrhoea with tegaserod only had one episode (median duration 2.5-3.5 days) that resolved spontaneously or with an antidiarrhoeal. With the exception of nausea, all other differences in adverse event rates between the tegaserod and placebo groups were $<1 \%$.

During first treatment, $2.2 \%$ of the tegaserod group and $1.1 \%$ of the placebo group discontinued treatment because of an adverse event. The difference was driven primarily by diarrhoea, which led to discontinuation in $0.9 \%$ of tegaserod patients and no placebo patients. During repeated treatment, the number of patients discontinuing treatment because of an adverse event was similar in the tegaserod and placebo groups $(0.8 \%$ and $0.6 \%$, respectively). No deaths were reported during the study. There were no cases of ischaemic colitis during the study period and no clinically relevant changes in laboratory values, ECG parameters, or vital signs.

\section{DISCUSSION}

This large, multinational, randomised, placebo controlled study is the first to report use of a repeated treatment design, as suggested by the CHMP for the evaluation of drugs intended for short term use in IBS-C. ${ }^{4}$ In most patients, IBS symptoms are intermittent, with symptomatic episodes

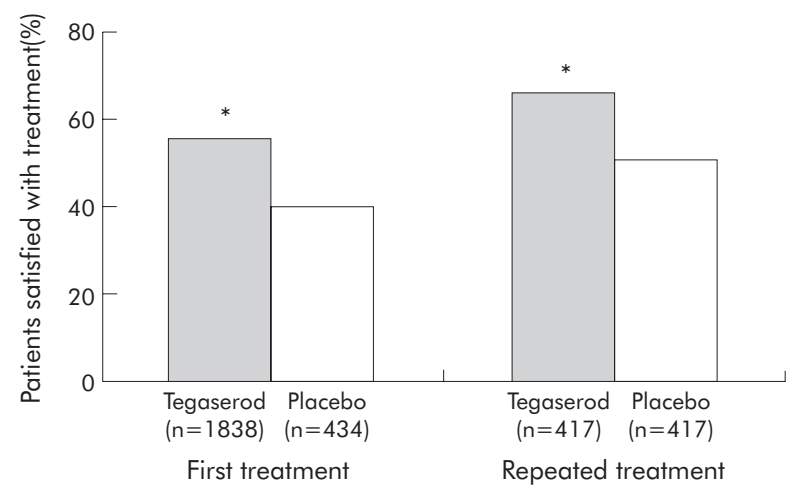

Figure 4 Patient satisfaction with treatment after the first and repeated treatment. During both treatment periods, overall treatment satisfaction satisfaction was significantly ( ${ }^{*} p<0.05$ ) greater with tegaserod than placebo. For repeated treatment, both tegaserod and placebo groups had received tegaserod in first treatment.
Table 4 Most frequent adverse events $\geqslant 1 \%$ in any group), regardless of study drug relation

\begin{tabular}{|c|c|c|c|c|}
\hline & \multicolumn{2}{|c|}{ First treatment } & \multicolumn{2}{|c|}{ Repeated treatment ${ }^{*}$} \\
\hline & $\begin{array}{l}\text { Tegaserod } \\
(n=2132), \\
n(\%)\end{array}$ & $\begin{array}{l}\text { Placebo } \\
\text { (n=525), } \\
n(\%)\end{array}$ & $\begin{array}{l}\text { Tegaserod } \\
(\mathrm{n}=487), \\
\mathrm{n}(\%)\end{array}$ & $\begin{array}{l}\text { Placebo } \\
(n=494), \\
n(\%)\end{array}$ \\
\hline Headache & $118(5.5)$ & $26(5.0)$ & $20(4.1)$ & $18(3.6)$ \\
\hline Diarrhoea & $81(3.8) \dagger$ & $3(0.6)$ & $9(1.8) \ddagger$ & $2(0.4)$ \\
\hline Abdominal pain & $48(2.3)$ & $13(2.5)$ & $5(1.0)$ & $6(1.2)$ \\
\hline Nausea & $47(2.2)$ & $6(1.1)$ & $2(0.4)$ & $2(0.4)$ \\
\hline Nasopharyngitis & $46(2.2)$ & $8(1.5)$ & $6(1.2)$ & $5(1.0)$ \\
\hline Influenza' & $24(1.1)$ & $7(1.3)$ & $1(0.2)$ & $2(0.4)$ \\
\hline Abdominal pain upper & r $23(1.1)$ & $3(0.6)$ & $3(0.6)$ & $2(0.4)$ \\
\hline Back pain & $20(0.9)$ & $8(1.5)$ & $5(1.0)$ & $5(1.0)$ \\
\hline Dyspepsia & $11(0.5)$ & $5(1.0)$ & $2(0.4)$ & $2(0.4)$ \\
\hline Urinary tract infection & $11(0.5)$ & $6(1.1)$ & $5(1.0)$ & $3(0.6)$ \\
\hline Dysmenorrhoea & $11(0.5)$ & $3(0.6)$ & $2(0.4)$ & $5(1.0)$ \\
\hline \multicolumn{5}{|c|}{$\begin{array}{l}\text { *Includes only first treatment tegaserod patients who received repeated } \\
\text { treatment. } \\
t p<0.0001 \text {, tegaserod } v \text { placebo using Fisher's exact test (post hoc). } \\
\mp p=0.04 \text {, tegaserod } v \text { placebo using Fisher's exact test (post hoc). }\end{array}$} \\
\hline
\end{tabular}

interrupted by symptom free days. ${ }^{18} 19$ The cyclical nature of IBS- $C$ makes repeated treatment an attractive management option, but fluctuations of stool pattern and symptom profile over time are major challenges when designing a controlled study of repeated treatment. ${ }^{20}$

The present study establishes that tegaserod is effective and well tolerated during both first and repeated treatment in women with IBS-C, with repeated treatment evaluated only for those who responded to first treatment. Tegaserod was associated with rapid and sustained relief of all IBS symptoms during first and repeated treatment, with statistical significance versus placebo reached between days $1-3$ for daily recorded symptoms, maintained through day 7 and for weeks 2-4. The clinical benefits of tegaserod observed with the primary variables (response in relation to relief of overall IBS symptoms and relief of abdominal discomfort/pain during both first and repeated treatment) were confirmed by its effect on secondary efficacy variables including relief of constipation, reduced intensity of abdominal discomfort/pain and bloating, more frequent bowel movements, and improved stool consistency. Following cessation of treatment and entry to the TFI, there was no evidence of a rebound effect as symptoms did not return with increased severity. The results from this study are consistent with those from studies that investigated use of tegaserod continuously for 12 weeks. ${ }^{2} 3910$ Importantly, despite the short treatment duration in the current study, the observed clinical benefits were associated with significant improvements in QoL, improved work 
productivity, and a higher level of patient satisfaction with tegaserod than placebo.

Concerns have been raised previously regarding the design of IBS clinical trials that involve re-randomisation. ${ }^{20}$ These concerns relate to the definition of recurrence and the possibility of treatment related differences in the course of recurrence with the risk of subsequent re-randomisation compromising the treatment blind. In this study, recurrence was defined as the absence of satisfactory relief of overall IBS symptoms and abdominal discomfort/pain for three or more out of four consecutive weeks. Symptom recurrence during the TFI followed a quasi-linear course, for both the tegaserod and placebo groups, with similar median time to recurrence, indicating that the treatment blind is unlikely to have been compromised. The median time to recurrence was similar in an uncontrolled study of IBS-C that used the same recurrence criterion (based on overall relief alone). ${ }^{21}$ In the present study, the severity of symptoms following recurrence was less pronounced than at baseline before first treatment. However, repeated treatment with tegaserod still provided a significant benefit compared with placebo.

Overall, tegaserod provides clinically meaningful benefit to women with IBS-C. In patients who have responded to a first course of treatment, repeated treatment with tegaserod is very effective with a NNT as low as 5.0 for relief of abdominal discomfort/pain and 5.9 for relief of overall IBS symptoms.

This study of repeated treatment is an important advance in the approach to the management of patients with IBS. The data provide new insights into the efficacy of tegaserod in women with IBS-C when used for short term, repeated treatment of symptomatic exacerbations.

\section{ACKNOWLEDGEMENTS}

We thank Brigitte Nault, MSc, Rebecca Emmons, PhD, and Victoria Barghout, PharmD (Novartis Pharma, AG) for their assistance in executing a complex trial and Gervais Tougas MD and Christopher McBurney PharmD (Novartis Pharma, AG) for assistance with the manuscript. We thank Jennifer Kelsey (Thomson Acumed) for editorial support. We also thank the following physicians for their participation in this study. Argentina: G Iantorno, A Zalar (Buenos Aires), R Castillo, C Cerisoli, B Gonzalez, L Soifer (Capital Federal), J German (Cordoba), R Pedrana (Rosario), J Fernandez (Tucuman); Austria: J Pechmann, T Stupnicki (Deutschlandsberg), G Brandstaetter (Graz), H Brunner (Vienna), P Knoflach (Wels); Belgium: E François (Anderlecht), M Van Outryve (Antwerpen), H Piessevaux (Bruxelles), G Robaeys (Genk), D De Looze (Gent), Ph Vergauwe (Kortrijk), J Tack (Leuven), E Louis (Liege); Canada: C Vanderkooy (Hamilton, ON), G Devroede (Sherbrooke, QUE); Chile: J Maira (Providencia-Santiago Chile), E Bachelet (Vina del Mar); Columbia: O Gutierrez, R Pina, L Sabbagh (Bogota), A Rengifo (Cali); Czech Republic: J Zeman (Decin), V Woznica (Most), L Douda (Plana nad Luznici), R Keil, K Lukas (Prague) D Pulgretova (Pribam-Zdabor); Denmark: S Kiilerich (Copenhagen), $\mathrm{T}$ Knudsen (Esbjerg), J Andersen (Frederikssund), P Bytzer (Glostrup), P Utzon (Holstebro), S Jensen (Kolding), T Havelund (Odense), A Malchow-Moeller (Svendborg), E Ejlersen (Vejle); Ecuador: E Coronel Mosquera (Cuenca), L Frugone (Guayaquil), W Argudo (Quito); Egypt: A El-Zayadi, F Thakeb, S Zakaria (Cairo); Finland: M Vauhkonen (Espoo), J Silvennoinen (Joensuu), K AlaHurula (Kemi), R Gronfors (Turku); France: S Musso (Eaunes), F Spilthooren (Evreux), C Magnani (L'aigle), J-B Churet (Le Prudet), S Boutboul (Marseille), G Mongin (Montpellier), J Marty (Murs Erigne), A Boye (Nantes), P Beignot Devalmont (Rouen), T Latté (St Julien des Landes), A Campagne (Tours), D Lejay (Vieux Conde); Germany: S Mueller-Lissner (Berlin), C Schmidt (Bonn), P Lex (Fuerth), M Karaus (Goettingen), T Herrmann (Heidelberg), S Gesenhues (Ochtrup), W Brandt (Potsdam/ Babelsberg), P Gnisa (Pulheim); Hungary: Z Tulassay (Budapest), I Racz (Gyor), L Ujszaszy (Miskolc), L Simon (Szekszard), Z Dobronte (Szombathely); Italy: A Francavilla (Bari), R Corinaldesi (Bologna), F Chilovi (Bolzano), G Minoli (Como), F Pacini (Firenze), V Savarino (Genova), S Pustorino (Messina), A Saggioro (Mestre), G Basilisco, G Bianchi Porro, P Testoni (Milano), S Vigneri (Palermo), G Corazza (Pavia), A Morelli (Perugia), F Polimeni (Reggio Calabria),
G Fornaciari (Reggio Emilia), G Gasbarrini (Roma), M Rizzetto (Torino), L Benini (Verona); The Netherlands: J van Selm (Alphen a/d Rijn), H Rol (Bennebroek), M Willink (Doetinchem), V van de Walle (Geleen/Leiden), P van Meurs (Hengelo), I. Ong (Hoogvliet), W. Croughs (Maastricht), P. Meurs (Soerendonk), P Haeck (Stadskanaal); New Zealand: M Lane, I Wallace (Auckland), A Ross (Christchurch), R Lubcke (Dunedin), D Shaw (Tauranga), J Wyeth (Wellington); Norway: O Høie (Arendal), A Tandberg (Bekkestua), C Bang (Bergen), K Vetvik (Mandal), E Øfjord (Paradis); Peru: M Alarcon Guevara, A Bussalleu, A MachadoMayuri, H Velazquez Chamochumbi (Lima); South Africa: $\mathrm{H}$ Grundling (Bloemfontein), H Bloch, T de Villiers, A Girdwood, S Schmidt, C Van Rensburg (Cape Town), N Aboo, F Makumbi (Durban), R Ally (Johannesburg), P van Eeden (Panorama), $\mathrm{H}$ Schneider (Parktown), P Spies (Pretoria); Spain: M Villagrasa (Badalona), M Vila-Costa (Martorrel), M Torres (Santa Coloma de Gramanet), M Minguez-Perez (Valencia), X Farres (Vic); Sweden: A Lasson (Boras), R Ekesbo (Dalby), A Friman (Degeberga), B Malmodin (Falun), C-P Anderberg, M Simren (Goteborg), E Hertervig (Lund), U-B Ericsson (Malmo), B Blomberg (Orebro), G Midhagen (Skovde), P Hellstrom, H Nyhlin, H Tornblom (Stockholm), M El-Salhy (Umea), P Berens (Uppsala); UK: J Playfair (Bath), A Wijnberg (Birmingham), D Haworth (Blackpool), R Przemioslo (Bristol), S Taylor (Chorley), C Nwokolo, A Smithers (Coventry), I Lodhi (Liverpool), G Dovey (Manchester), $\mathrm{H}$ Shaw (Reading), N Ahluwalia (Stockport); USA: T Loludice (Akron, OH), R Marks (Alabaster, AL), D Riff (Anaheim, CA), P Kashyap (Anniston, AL), A Watters (Arkansas City, KS), J Schwartz (Arlington Heights, IL), R Fadden (Beaver Falls, PA), L Ou-Tim (Birmingham, AL), A Zwick (Boca Raton, FL), J Witte (Boise, ID), S Friedman (Boston, MA), J Roddenberry (Bradenton, FL), U Rau (Braintree, MA), D Morin (Bristol, TN), B Hill (Chaska, MN), C Schmitt (Chattanooga, TN), T Smith (Chesterfield, MO), L Korman (Chevy Chase, MD), S Castillo (Chicago, IL), G Wiener (Chula Vista, CA), J Fidelholtz (Cincinnati, OH), H Giller (Clive, IA), R Folan, A Shafii (Colorado Springs, CO), J Popp (Columbia, SC), M Peshimam (Corona, CA), M Reynolds (Dallas, TX), B Shivakumar (Davenport, IA), H Maimon (Dayton, OH), D Maleki (Egg Harbor, NJ), V Kolli (El Paso, TX), J Perry (Endwell, NY), J LaSalle (Excelsior Springs, MO), Y Sherrer (Fort Lauderdale, FL), J Beckwith (Fort Worth, TX), D Cardona, P Jajodia, K Wingert (Fresno, CA), K Cohen (Golden, CO), M Goldstein (Great Neck, NY), J Cappa (Hartford, CT), S Behar (Hialeah, FL), M Lamet, W Schonfeld (Hollywood, FL), G Ergun, F Hochman, J Mitchell (Houston, TX), M Elmore, T Nowak (Indianapolis, IN), M Swaim (Jackson, TN), D Eskreis (Lake Success, NY), Goff, W Larson (Lakewood, WA), P Coleman (Lansing, MI), J Christensen (Las Vegas, NV), T Baber (Little Rock, AR), R Hansen (Littleton, CO), W Berry (Longmont, CO), L Chang, M Rosenberg, T Simmons (Los Angeles, CA), J Wo, R Wright (Louisville, KY), E Spiotta, L Wruble (Memphis, TN), H Schwartz (Miami, FL), D Dozer, J Geenen (Milwaukee, WI), S Brady (Naples, FL), D Gremillion, N Price (Nashville, TN), G Barton (North Little Rock, AR), M Grossman, P Miner (Oklahoma City, OK), S Duckor (Orange, CA), N Murali (Orangeburg, SC), B Short (Overland Park, KS), K Aqua (Palm Springs, FL), B Dolin (Peoria, IL), E Riffer (Phoenix, AZ), G Koval (Portland, OR), R Schwarz (Raleigh, NC), S Coble (Rolla, MO), D Harris (Salt Lake City, UT), C Horn, S Randall (San Antonio, TX), M Bennett, D Brandon (San Diego, CA), W Snape (San Francisco, CA), C Bedard (Seattle, WA), M Provenza (Shreveport, LA), O Gilliam (South Bend, IN), S Chen (Spokane, WA), R Cady, (Springfield, MO), D Chazen (Springfield, NJ), S Yates (The Colony, TX), M Raikhel (Torrance, CA), J Novick (Towson, MD), F Braunstein (Troy, NY), J McNerney (Tucson, AZ), H Tatum (Tulsa, OK), F Naffah (Warren, OH), D Wenzel (Wellesley Hills, MA), M Tabbaa (Westlake, OH), S Krumholz (West Palm Beach, FL), T Klein (Wichita, KS), R Holmes (Winston-Salem, NC).

\section{Authors' affiliations}

J Tack, Department of Gastroenterology, Centre for Gastroenterological Research, University of Leuven, Leuven, Belgium

S M-Lissner, Park-Klinik Weissensee, Humboldt University, Berlin, Germany

P Bytzer, Glostrup University Hospital, Copenhagen University, Copenhagen, Denmark

R Corinaldesi, Dipartimento di Medicina Interna e Gastroenterologia, Università degli Studi di Bologna, Bologna, Italy 
L Chang, Center for Neurovisceral Sciences and Womens Health at UCLA, and VAGLAHS, Los Angeles, CA, USA

A Viegas, Novartis Pharmaceuticals Corp, East Hanover, NJ, USA S Schnekenbuehl, C Dunger-Baldauf, P Rueegg, Novartis Pharma AG, Basel, Switzerland

The study was sponsored by Novartis Pharma AG.

Conflicts of interest: J Tack has no specific disclosures; he is listed in the Novartis Zelnorm Speakers' Bureau. S Müller-Lissner is and was involved in drug trials and acts as an advisor for several pharmaceutical companies including Novartis. He is also listed in the Novartis Zelnorm Speakers' Bureau. P Bytzer has no conflicts of interest to declare. $\mathrm{R}$ Corinaldesi has no conflicts of interest to declare. L Chang has received grant support from Novartis and is listed in the Novartis Zelnorm Speakers' Bureau. A Viegas is a Novartis employee. S Schnekenbuehl is a Novartis employee. C Dunger-Baldauf is a Novartis employee. P Rueegg is a Novartis employee

\section{REFERENCES}

1 Camilleri M, Choi MG. Review article: irritable bowel syndrome. Aliment Pharmacol Ther 1997;11:3-15.

2 Müller-Lissner SA, Fumagalli I, Bardhan KD, et al. Tegaserod, a 5-HT receptor partial agonist, relieves symptoms in irritable bowel syndrome patients with abdominal pain, bloating and constipation. Aliment Pharmacol Ther 2001;15:1655-66.

3 Novick J, Miner P, Krause R, et al. A randomized, double-blind, placebocontrolled trial of tegaserod in female patients suffering from irritable bowel syndrome with constipation. Aliment Pharmacol Ther 2002;16:1877-88.

4 CPMP. Points to consider on the evaluation of medicinal products for the treatment of irritable bowel syndrome. 2003(CPMP/EWP/785/97).

5 Uscanga-Dominguez L, Cohen Munoz V. Relapse of symptoms following withdrawal of tegaserod treatment in irritable bowel syndrome with constipation (IBS-C). Gastroenterology 2003; 124(Suppl 1):A571.

6 Müller-Lissner S, Holtmann G, Loeffler $H$, et al. Tegaserod is effective in the retreatment of irritable bowel syndrome with constipation (IBS-C).

Gastroenterology 2003;124(Suppl 1):A574.
7 Bardhan KD, Forbes A, Marsden C, et al. The effects of withdrawing tegaserod treatment in comparison with continuous treatment in irritable bowel syndrome patients with abdominal pain/discomfort, bloating and constipation: a clinical study. Aliment Pharmacol Ther 2004;20:213-22.

8 Drossman DA, Corazziari E, Talley NJ, et al. Rome II: The functional gastrointestinal disorders, 2nd ed. McLean, VA: Degnon Associates, 2000.

9 Kellow J, Lee OY, Chang FY, et al. An Asia-Pacific, double blind, placebo controlled, randomised study to evaluate the efficacy, safety, and tolerability of tegaserod in patients with irritable bowel syndrome. Gut 2003;52:671-6.

10 Nyhlin H, Bang C, Elsborg L, et al. A double-blind, placebo-controlled, randomized study to evaluate the efficacy, safety and tolerability of tegaserod in patients with irritable bowel syndrome. Scand J Gastroenterol 2004;39:119-26.

11 Dunger-Baldauf C, Nyhlin H, Rueegg P, et al. Subject's global assessment of satisfactory relief as a measure to assess treatment effect in clinical trials in irritable bowel syndrome (IBS). Am J Gastroenterol 2003;98:S269.

12 Mangel AW, Hahn BA, Heath AT, et al. Adequate relief as an endpoint in clinical trials in irritable bowel syndrome. J Int Med Res 1998;26:76-81

13 Patrick D, Drossman D, Frederick I, et al. Quality of life in persons with irritable bowel syndrome: development and validation of a new measure. Dig Dis Sci 1998;43:400-11.

14 Reilly MC, Bracco A, Ricci JF, et al. The validity and accuracy of the Work Productivity and Activity Impairment questionnaire - irritable bowel syndrome version (WPAl:IBS). Aliment Pharmacol Ther 2004;20:459-67.

15 The EuroQol Group. EuroQol-a new facility for the measurement of healthrelated quality of life. The EuroQol Group. Health Policy 1990;16:199-208.

16 Rabin R, de Charro F. EQ-5D: a measure of health status from the EuroQol Group. Ann Med 2001;33:337-43.

17 Weeks DL, Noteboom JT. Using the number needed to treat in clinical practice. Arch Phys Med Rehabil 2004;85:1729-31.

18 Hahn B, Watson $M$, Yan S, et al. Irritable bowel syndrome symptom patterns frequency, duration, and severity. Dig Dis Sci 1998;43:2715-18.

19 Camilleri M. Management of the irritable bowel syndrome. Gastroenterology $2001 ; 120: 652-68$

20 Corazziari E, Bytzer $P$, Delvaux $M$, et al. Clinical trial guidelines for pharmacological treatment of irritable bowel syndrome. Aliment Pharmacol Ther 2003; 18:569-80.

21 Müller-Lissner S, Holtmann G, Rueegg P, et al. Tegaserod is effective in the initial and retreatment of irritable bowel syndrome with constipation. Aliment Pharmacol Ther 2005;21:11-20.

\section{EDITOR'S QUIZ: GI SNAPSHOT}

\section{Answer}

From question on page 1671

Computed tomography (CT) (figl) showed loops of thick walled distal small bowel and a $3 \times 2 \mathrm{~cm}$ non-calcified mass within the bowel mesentery, surrounded by streaky fibrosis. There was no associated lymphadenopathy. Appearances were in keeping with a small bowel carcinoid tumour.

The histology slide of the resected bowel and mesentery (fig 2) confirmed an infiltrating carcinoid tumour (right arrow) associated with sclerotic encasement and constriction of the mesenteric vessels (left arrow). This compromised the vascular supply leading to intestinal ischaemia, which was the cause for her symptoms rather than carcinoid syndrome.

Diarrhoea is a common feature of carcinoid syndrome and relates to the production and systemic release of serotonin and other peptide hormones by hepatic metastases. However, this patient's liver ultrasound was normal. Another well recognised complication of midgut carcinoids is sclerosis of the mesenteric vessels due to the direct effect of peptide secretion on the local blood vessels. This can result in bowel ischaemia or even infarction.

Chronic intestinal ischaemia has been found at laparotomy in up to one third of patients with advanced midgut carcinoids. ${ }^{1}$ Techniques such as three dimensional CT angiography enable visualisation of the tumour and its relationship to the local vessels. Use of conventional angiography is diminishing but has a role when imaging studies are equivocal. Exploratory surgery is often required to confirm the diagnosis. Definitive management is surgical, with careful dissection of the vasculature and resection of the affected bowel and mesenteric segment. However, short

\section{References}

1 Makridis C, Oberg K, Juhlin C, et al. Surgical treatment of midgut carcinoid tumors. World J Surg 1990;14:377-85.

2 Ohrvall U, Eriksson B, Juhlin C, et al. Method for dissecting metastases in midgut carcinoid tumors. World J Surg 2000;24:1402-8. 